\title{
Dural arteriovenous fistula-induced thalamic dementia: report of 4 cases
}

\author{
${ }^{*}$ Terrence F. Holekamp, MD, PhD, ${ }^{1}$ Matthew E. Mollman, BS, ${ }^{1}$ Rory K. J. Murphy, MD, ${ }^{1}$ \\ Grant R. Kolar, MD, PhD, ${ }^{2}$ Neha M. Kramer, MD, ${ }^{5}$ Colin P. Derdeyn, MD, ${ }^{1,4,5}$ \\ Christopher J. Moran, MD, ${ }^{1,4}$ Richard J. Perrin, MD, PhD, ${ }^{6}$ Keith M. Rich, MD, ${ }^{1,4}$ \\ Giuseppe Lanzino, MD, ${ }^{3}$ and Gregory J. Zipfel, MD ${ }^{1,5}$
}

\begin{abstract}
Departments of ${ }^{1}$ Neurological Surgery, ${ }^{2}$ mmunology, ${ }^{5}$ Neurology, and ${ }^{6}$ Pathology, Washington University School of Medicine in St. Louis; " Department of Radiology, Mallinckrodt Institute of Radiology, Washington University School of Medicine in St. Louis, Missouri; and ${ }^{3}$ Department of Neurological Surgery, Mayo Clinic, Rochester, Minnesota
\end{abstract}

\begin{abstract}
Nonhemorrhagic neurological deficits are underrecognized symptoms of intracranial dural arteriovenous fistulas (dAVFs) having cortical venous drainage. These symptoms are the consequence of cortical venous hypertension and portend a clinical course with increased risk of neurological morbidity and mortality. One rarely documented and easily misinterpreted type of nonhemorrhagic neurological deficit is progressive dementia, which can result from venous hypertension in the cortex or in bilateral thalami. The latter, which is due to dAVF drainage into the deep venous system, is the less common of these 2 dementia syndromes. Herein, the authors report 4 cases of dAVF with venous drainage into the vein of Galen causing bithalamic edema and rapidly progressive dementia. Two patients were treated successfully with endovascular embolization, and the other 2 patients were treated successfully with endovascular embolization followed by surgery. The radiographic abnormalities and presenting symptoms rapidly resolved after dAVF obliteration in all 4 cases. Detailed descriptions of these 4 cases are presented along with a critical review of 15 previously reported cases. In our analysis of these 19 published cases, the following were emphasized: 1) the clinical and radiographic differences between dAVF-induced thalamic versus cortical dementia syndromes; 2) the differential diagnosis and necessary radiographic workup for patients presenting with a rapidly progressive thalamic dementia syndrome; 3) the frequency at which delays in diagnosis occurred and potentially dangerous and avoidable diagnostic procedures were used; and 4) the rapidity and completeness of symptom resolution following dAVF treatment.
\end{abstract}

http://thejns.org/doi/abs/10.3171/2015.5.JNS15473

KEY WORDS dural arteriovenous fistula; cortical venous hypertension; thalamic edema; nonhemorrhagic neurological deficit; thalamic dementia; vascular disorders

$\mathrm{I}$ NTRACRANIAL dural arteriovenous fistulas (dAVFs) are rare vascular malformations characterized by a direct shunt between dural arteries and a venous sinus and/ or cortical vein. Most are idiopathic, though some can be related to prior surgery, trauma, or dural sinus thrombosis. ${ }^{8-10,17,30,44,47,55,64,71,80}$ Modes of presentation include 1) intracranial hemorrhage (ICH) due to cortical venous hypertension, 2) nonhemorrhagic neurological deficits (NHNDs) due to cortical venous hypertension, 3) symptoms of increased sinus drainage including pulsatile tinnitus and ophthalmological phenomenon, and 4) incidental. ${ }^{6,710}$ The natural history of dAVFs is strongly linked to the absence or presence of drainage into cortical veins, which is termed cortical venous drainage (CVD). Borden-Shucart Type 1 dAVFs (those without CVD) rarely present with ICH or NHNDs and have a benign natural history ${ }^{66,68,72}$ Borden-Shucart Type 2 and 3 dAVFs (those with CVD) commonly present with ICH or NHNDs and can have an aggressive natural history. $3,9,10,19,24,71,80,81,84,91$ In recent years, $\mathrm{we}^{72}$ and others ${ }^{24,71}$ have shown that mode of presentation also impacts natural history, as patients harboring dAVFs with CVD who present with ICH or NHNDs are at significantly higher risk for new neurological events as compared with those who present incidentally or with symptoms of increased sinus drainage. ${ }^{19,66,68}$ Based on these data, we proposed a modification to the

ABBREVIATIONS CVD = cortical venous drainage; $\mathrm{dAVF}=$ dural arteriovenous fistula; $I \mathrm{CH}=$ intracranial hemorrhage; $\mathrm{NHND}=$ nonhemorrhagic neurological deficit. SUBMITTED March 9, 2015. ACCEPTED May 14, 2015.

INCLUDE WHEN CITING Published online November 20, 2015; DOI: 10.3171/2015.5.JNS15473.

* Dr. Holekamp and Mr. Mollman contributed equally to this work. 
TABLE 1. Modified classification of intracranial dAVFs*

\begin{tabular}{cccccccccc}
\hline Zipfel & $\begin{array}{c}\text { Borden-Shucart } \\
\text { Type }\end{array}$ & $\begin{array}{c}\text { Cognard } \\
\text { Type }\end{array}$ & $\begin{array}{c}\text { Venous } \\
\text { Drainage }\end{array}$ & CVD & CVH & $\begin{array}{c}\text { Presents w/ } \\
\text { ICH or NHND }\end{array}$ & $\begin{array}{c}\text { ICH } \\
\text { Risk (\%) }\end{array}$ & $\begin{array}{c}\text { Death } \\
\text { Risk (\%) }\end{array}$ & Treatment \\
\hline 1 & I & I, Ila & Dural sinus & No & No & No & $<1$ & 0 & Elective for intractable symptoms \\
\hline $2 \mathrm{~A}$ & II & IIb, Ila + b & Dural sinus & Yes & No & No & $1.4-1.5$ & 0 & Elective to prevent ICH/NHND \\
\hline $2 S$ & II & IIb, Ila + b & Dural sinus & Yes & Yes & Yes & $7.4-7.6$ & 3.8 & Early to prevent ICH/NHND \\
\hline $3 \mathrm{~A}$ & III & III, IV, V & Cerebral vein & Yes & No & No & $1.4-1.5$ & 0 & Elective to prevent ICH/NHND \\
\hline $3 S$ & III & III, IV, V & Cerebral vein & Yes & Yes & Yes & $7.4-7.6$ & 3.8 & Early to prevent ICH/NHND \\
\hline
\end{tabular}

$\mathrm{CVH}=$ cortical venous hypertension.

* Modified from Zipfel et al: Neurosurg Focus 26(5):E14, 2009. This modification to the Borden-Shucart angiographic classification system allows for risk stratification of patients with asymptomatic (2A and $3 \mathrm{~A})$ or symptomatic ( $2 \mathrm{~S}$ and $3 \mathrm{~S})$ presentation.

Borden-Shucart classification system-based not only on angiographic appearance but also mode of presentationto permit more accurate risk stratification and assist with clinical decision making for the type and timing of dAVF treatment (Table 1). ${ }^{68,91}$

One relatively underappreciated type of NHND is progressive dementia resulting from dAVF-induced cortical venous hypertension, though correct diagnosis and treatment is increasing, thanks to improved imaging techniques. ${ }^{18,79}$ Dural AVF-induced progressive dementia can be differentiated as either cortical or thalamic in origin-2 categories that have relatively distinct patterns of clinical symptomatology $y^{18,54,62,80,85}$ and highly specific venous outflow patterns..$^{18,80}$ Of the two, dAVFinduced thalamic dementia is less frequent, with only 15 published cases reported in the literature to date. All were individual case reports, and several lacked adequate clinical, radiographic, and/or treatment specifics to permit detailed assessment as to manner of presentation, underlying hemodynamic pathophysiology, and long-term outcome. ${ }^{18,21-23,32,49,53,62,65,73,76-78,86,88}$ None provided a comprehensive literature review.

Here, we report 4 cases of dAVF with CVD involving the vein of Galen that presented with a rapidly progressive thalamic dementia syndrome. The specific pattern of presentation, diagnostic imaging findings, method of treatment, and long-term patient outcome as well as a critical review of the literature are provided. Emphasis is placed on the differential diagnosis of this rare condition, the appropriate radiographic workup, the ease at which this condition can be misdiagnosed and/or potentially dangerous diagnostic procedures such as stereotactic biopsy used, and the rapidity and completeness by which the presenting symptoms can resolve.

\section{Case Reports}

Case 1

A 53-year-old right-handed man with a remote history of motor vehicle accident was admitted with a 10-day history of worsening confusion and memory problems. His examination revealed profound short- and long-term memory impairment, attention deficit, associative prosopagnosia, moderately severe verbal fluency and comprehension impairments, and emotional lability. He also exhibited constant moderately coherent provoked confabulation.
His Mini-Mental State Examination score was 24/30 (-4 orientation, -2 recall). Brain MRI demonstrated symmetric bilateral thalamic FLAIR signal hyperintensities and subtle, patchy gadolinium enhancement (Fig. 1A-C). Cerebral angiography demonstrated a modified Borden-Shucart Type 2S dAVF located near the confluence of the vein of Galen and straight sinus with arterial supply primarily from both middle meningeal arteries and the inferolateral trunks of the internal carotid arteries (Fig. 1D). Venous drainage occurred via anterograde flow directly into the patent straight sinus, as well as retrograde flow through a vermian vein and the vein of Galen. The dAVF was successfully embolized with ethylene vinyl alcohol (Onyx) using a transarterial approach via the posterior division of the left middle meningeal artery (Fig. 1F).

The patient's mental status began to improve during his hospitalization, and he was discharged home 6 days later. Brain MRI performed 2 years after embolization demonstrated complete resolution of bithalamic edema (Fig. 1E). MR angiography at 1 and 2 years after treatment revealed no evidence of recurrent dAVF. Neuropsychological assessment 1 year after embolization, including Wechsler Memory Scale III, revealed generally average function with only mild to moderate deficits in verbal fluency and memory recall (Working Memory Index 88, Visual Immediate Index 103, Visual Delayed Index 94, Confrontational Picture Naming 59/60, Verbal Memory Recall was $81 \%$ ). His performance on all other tests was unimpaired. At the 6-year follow-up his Mini-Mental State Examination score was 30/30.

\section{Case 2}

A 59-year-old right-handed man was admitted with a 5-day history of altered mental status. His examination revealed severe short- and long-term memory deficits, mild verbal fluency impairment, and associative confabulation. CT demonstrated right thalamic hypoattenuation and subtle left posterior thalamic contrast enhancement (Fig. 2A and B). MRI revealed asymmetrical, bithalamic FLAIR hyperintensities (Fig. 2C). Cerebral angiography demonstrated a modified Borden-Shucart Type 3S tentorial dAVF deriving arterial supply from small branches of the left occipital artery as well as branches of both posterior meningeal arteries (Fig. 2D). Venous drainage was retrograde through an enlarged superior vermian vein, which refluxed into the vein of Galen and both internal cerebral 

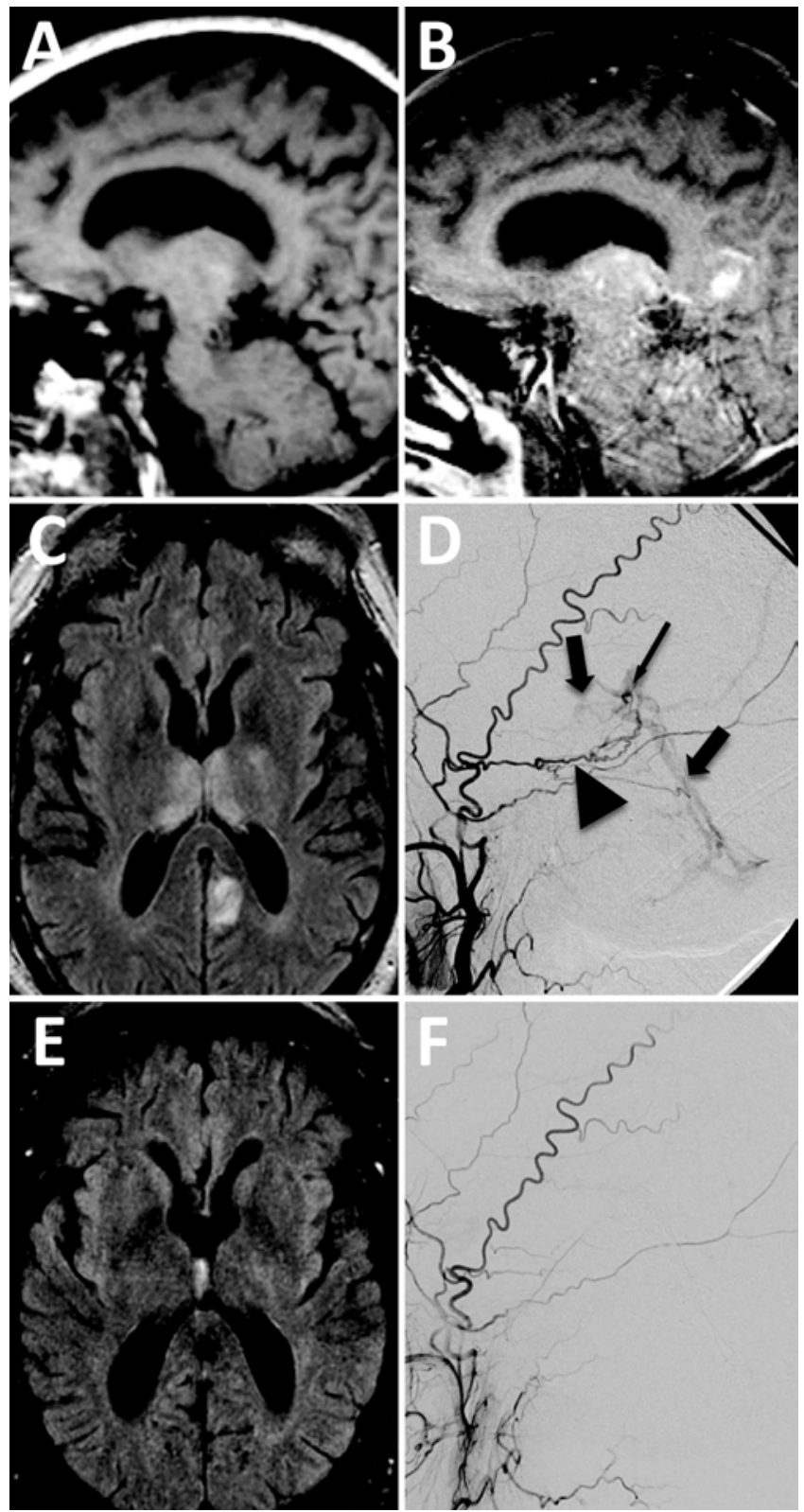

FIG. 1. Case 1. A-D: Images obtained at the time of diagnosis. Sagittal T1-weighted MR image without gadolinium showing no abnormality (A). Sagittal T1-weighted MR image with gadolinium showing bithalamic enhancement (B). FLAIR MR image showing medial bithalamic hyperintensities (C). Left lateral external carotid angiogram showing a modified Borden-Shucart Type 2S dAVF at the confluence of the vein of Galen and straight sinus (arrow) with arterial supply from the left middle meningeal artery (arrowhead) and venous drainage via anterograde flow into the straight sinus as well as retrograde flow into both internal cerebral veins (block arrows) (D). E and F: Images obtained 6 weeks after endovascular embolization of dAVF. FLAIR MRI showing resolution of bithalamic hyperintensities $(E)$. Left lateral external carotid angiogram showing complete obliteration of the dAVF (F).

veins. A focally occlusive thrombus within the distal segment of the straight sinus impaired normal outflow. Transvenous endovascular coiling through the straight sinus and vermian vein successfully obliterated the dAVF (Fig. 2F).

The patient's mental status began to improve during

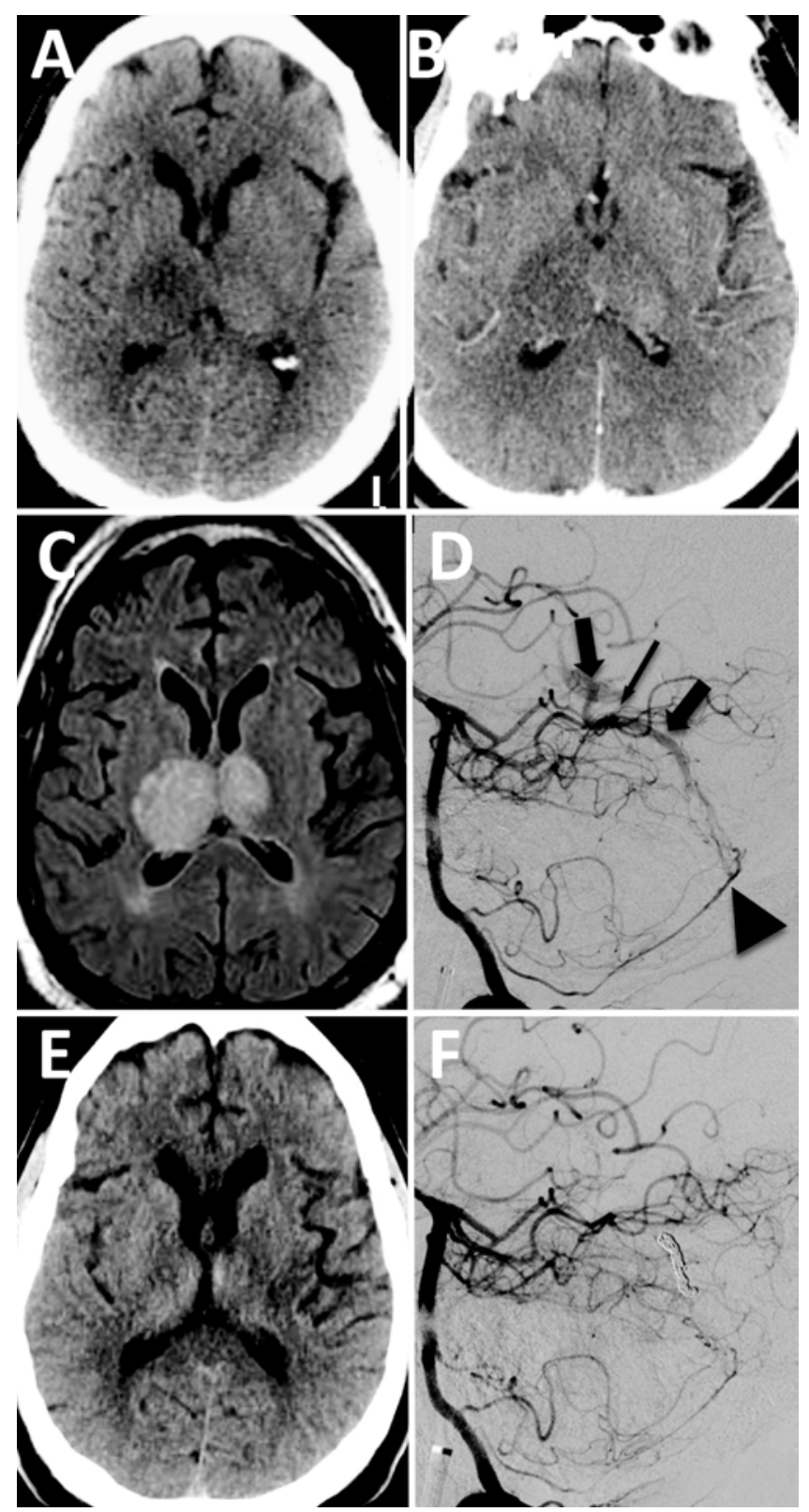

FIG. 2. Case 2. A-D: Images obtained at the time of diagnosis. Axial noncontrast and contrast CT scans showing subtle left posterior thalamic enhancement and right thalamic hypoattenuation (A and B); FLAIR $M R I$ showing left thalamic hyperintensities on the right more than on the left (C). Oblique right vertebral artery angiogram demonstrating a Modified Borden-Shucart Type 3S dAVF (thin arrow) deriving arterial supply from small branches of the right posterior meningeal artery (arrowhead). Venous drainage occurred via an enlarged vermian vein, refluxing through the vein of Galen into both internal cerebral veins (block arrows) (D). E and F: Images obtained 7 weeks after endovascular embolization of dAVF. Axial noncontrast CT showing resolution of right thalamic hypoattenuation (E). Oblique right vertebral artery angiogram demonstrates complete disconnection of the dAVF (F). A pretreatment postgadolinium MR image and a posttreatment MR image were unavailable.

his hospitalization, and he was discharged to a rehabilitation facility 7 days later. A head CT obtained 7 weeks after treatment demonstrated complete resolution of the thalamic edema (Fig. 2E). He was eventually discharged 
home, where his mental status continued to improve, according to his family. Unfortunately, the patient died of a myocardial infarction approximately 3 months after treatment, making further clinical and radiographic assessments impossible.

\section{Case 3}

A 60-year-old right-handed man was admitted after 4 days of rapidly worsening confusion and memory deficits. Electroencephalography showed frontal slowing, and brain MRI demonstrated asymmetrical bilateral thalamic FLAIR hyperintensities with moderate heterogeneous gadolinium enhancement (Fig. 3A-C). Due to this enhancement, as well as PET scan results consistent with hypermetabolism, neoplasms such as high-grade glioma and lymphoma were included in the differential diagnosis. This prompted a stereotactic biopsy, which was aborted after obtaining only 2 cores when bleeding was noted from the biopsy needle. CT scanning performed postprocedure showed a small, right thalamic hemorrhage. Pathology revealed moderate gliosis, hyalinized dilated microvascular changes, petechial hemorrhages, and patchy microinfarctions (Fig. 4). Given the patient's clinical history, these histology results were considered potentially consistent with Wernicke encephalopathy. Despite 6 weeks of vitamin supplementation for alcohol abuse, the patient's mental status continued to worsen. Cerebral angiography was then performed, which demonstrated a modified Borden-Shucart Type 3S torcular dAVF supplied by branches of the right occipital artery. Venous drainage was retrograde through a dilated vermian vein into the vein of Galen and internal cerebral veins (Fig. 3D). No filling of the straight sinus was noted, consistent with thrombosis. Transarterial Onyx embolization through the right occipital artery branches was performed, but vermian CVD persisted. Two days later, a midline suboccipital craniotomy was performed for clip ligation of the CVD. Intraoperative angiography demonstrated complete dAVF obliteration (Fig. 3F).

The patient's mental status began to improve during the hospitalization, and he was discharged to a rehabilitation facility 2 days later. Brain MRI performed 6 months after treatment showed complete resolution of thalamic FLAIR hyperintensities (Fig. 3E) and the associated gadolinium enhancement. His cognitive function returned to normal, and he resumed work as a truck driver. At 3-year followup his Mini-Mental State Examination score was 30/30 and the patient's wife felt that his cognitive function was even better than his prediagnosis baseline.

Case 4

A 71-year-old right-handed man was admitted after 6 months of progressively worsening forgetfulness, attention deficit, confusion, and daytime sleepiness. Four weeks prior to presentation, he had developed mild leftsided weakness and left-hand numbness that remained unevaluated until his rapid cognitive decline became more apparent. His examination revealed hypersomnolence and Kokmen Short Test of Mental Status score of 30/38 (-2 orientation, -1 attention, -1 calculation, -1 information, -3 recall). He also exhibited mild left-sided weakness in
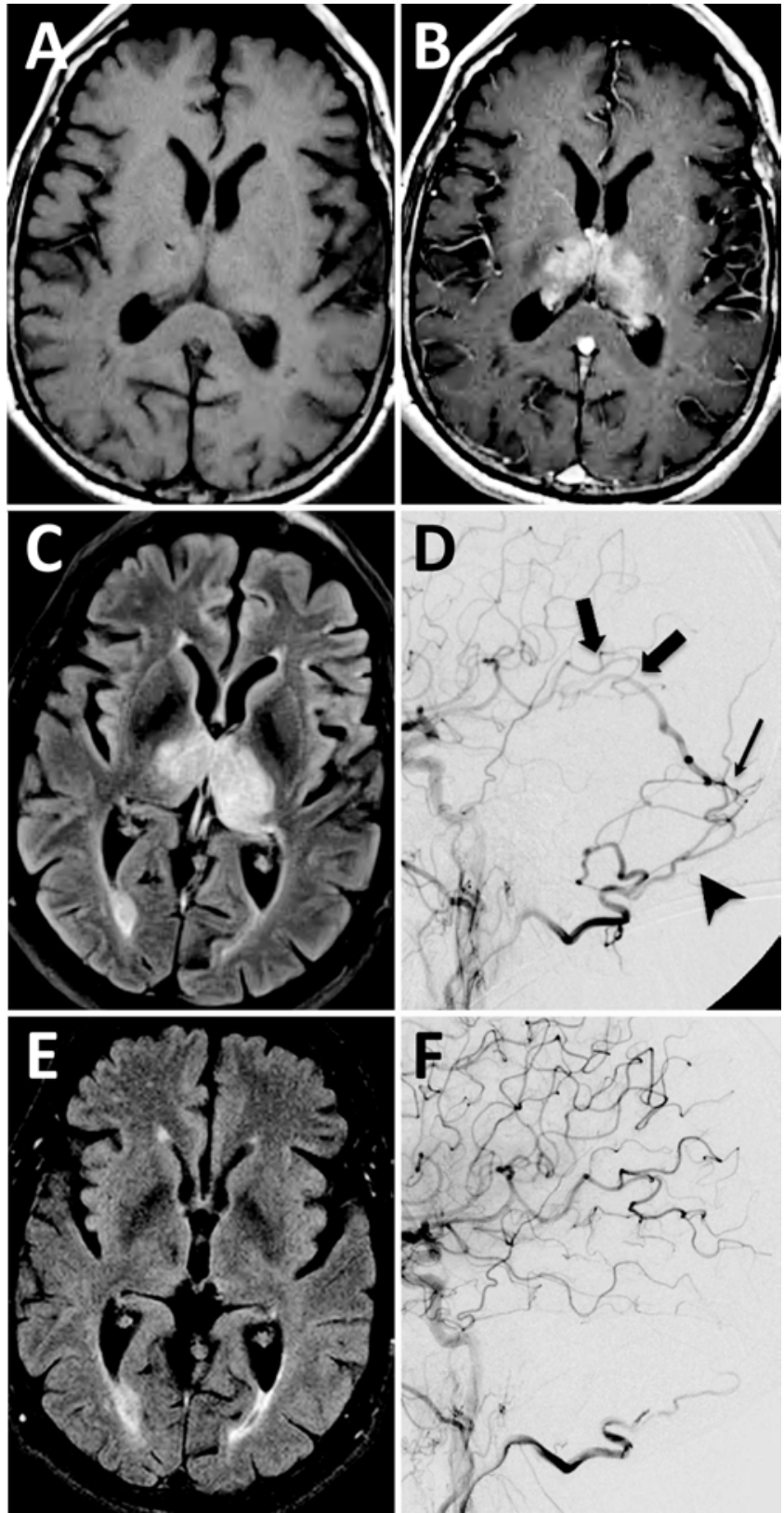

FIG. 3. Case 3. A-D: Images obtained at the time of diagnosis. T1weighted MR image without gadolinium showing no abnormality (A). T1weighted MR image with gadolinium showing enhancement in bilateral thalami (B). FLAIR MR image showing left greater than right bilateral thalamic T2 signal hyperintensities (C). Right lateral common carotid angiogram demonstrating a Modified Borden-Shucart Type 3S (arrow) deriving arterial supply from the right occipital artery (arrowhead). Venous drainage occurred via an enlarged right tentorial vein and then refluxed into the vein of Galen and both internal cerebral veins (block arrows, D). E and F: Images obtained 6 weeks after surgical ligation of the dAVF. FLAIR MR image showing resolution of bithalamic hyperintensities (E). Right lateral common carotid angiogram showing complete obliteration of the $d A V F(F)$.

an upper motor neuron pattern. Brain MRI demonstrated asymmetrical bilateral thalamic FLAIR hyperintensities and moderate heterogeneous bithalamic gadolinium enhancement (Fig. 5A-C). MR venography suggested a vas- 


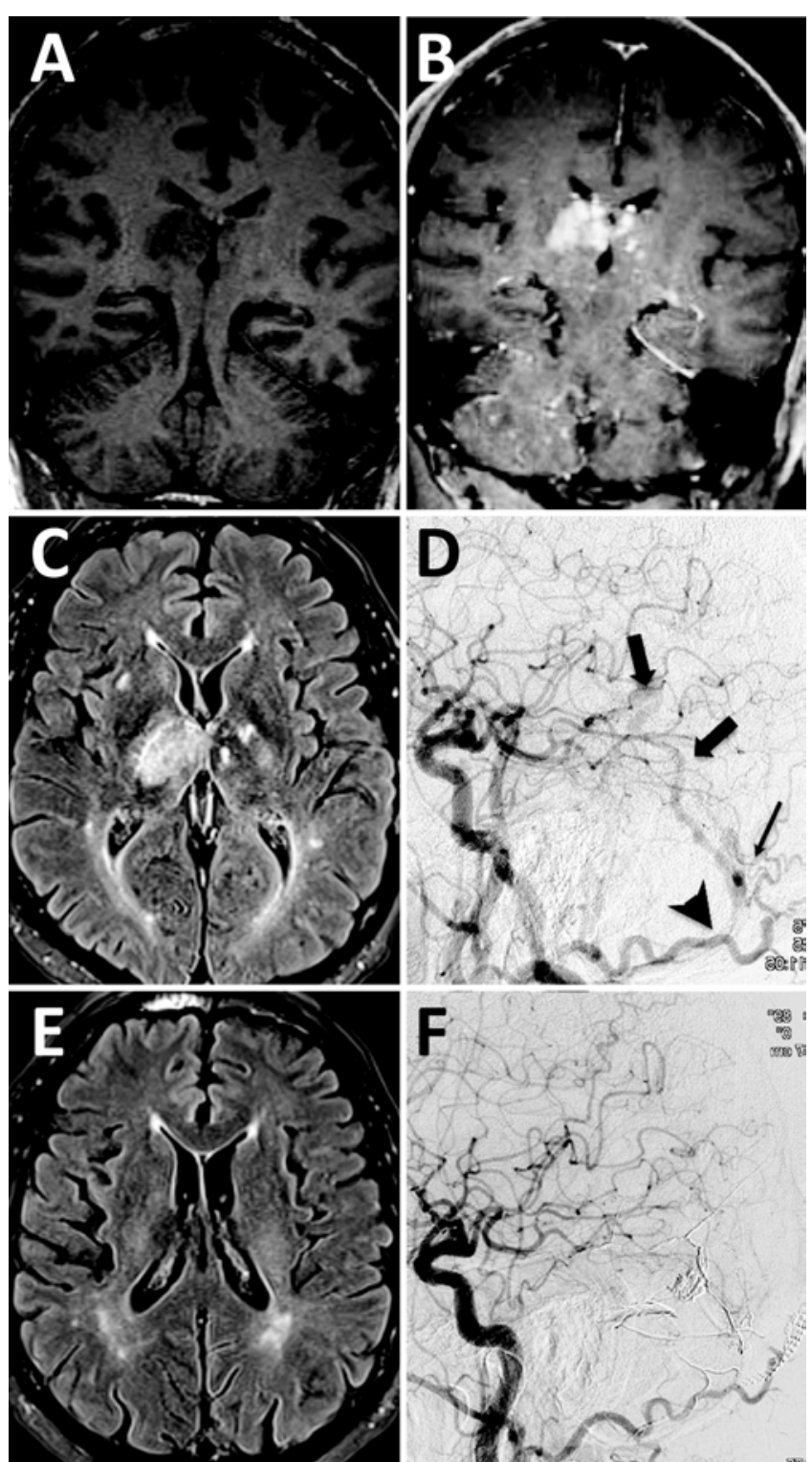

FIG. 4. Case 4. A-D: Images obtained at the time of diagnosis. Coronal T1-weighted MR image without gadolinium showing right thalamic hypointensity (A). Coronal T1-weighted MR image with gadolinium showing right greater than left bithalamic enhancement (B). FLAIR MR image showing right greater than left bithalamic hyperintensities (C). Right lateral common carotid angiogram, demonstrating a Modified BordenShucart Type 3S dAVF (arrow) deriving arterial supply from branches of the right middle meningeal and occipital arteries (arrowhead). Venous drainage occurred via an enlarged superior vermian vein, refluxing through the vein of Galen into both internal cerebral veins (block arrows, D). E and F: Images obtained 12 weeks after endovascular embolization of the dAVF. FLAIR MRI showing resolution of bithalamic hyperintensities (E). Right lateral common carotid angiogram showing complete obliteration of the $d A V F(F)$.

cular malformation in the posterior fossa including occlusion of the proximal straight sinus and enlarged cortical veins over the right parietal region. Catheter angiography demonstrated a modified Borden-Shucart Type 3S torcular dAVF with arterial supplies from branches of the occipital and middle meningeal arteries bilaterally (Fig. 5D).
Retrograde venous drainage occurred via a tortuous superior vermian vein with reflux into the vein of Galen as well as into the right parietal cortical veins. No filling of the straight sinus was seen, consistent with occlusion. Transarterial Onyx embolization was performed twice, though vermian CVD persisted after both procedures. A midline suboccipital craniotomy was then performed for clip ligation of the vermian CVD. Intraoperative angiography demonstrated complete dAVF obliteration (Fig. 5F). Two days after surgery the patient exhibited minor symptomatic recrudescence, and brain MRI demonstrated several small embolic infarcts in the supratentorial regions bilaterally. The etiology of these embolic events was unclear. The patient's condition improved following this event, and he was discharged to a rehabilitation facility.

Brain MRI performed 3 months after treatment demonstrated complete resolution of thalamic edema (Fig. $5 \mathrm{E}$ ), though several residual punctate areas of susceptibility-weighted signal intensity were noted within both thalami. MR venography also showed recanalization of the straight sinus and normalization of venous drainage. Clinical examination demonstrated improvement on the Kokmen Short Test of Mental Status to 34/38 (-1 attention, -3 recall). His family observed that he had undergone a remarkable recovery back to his cognitive baseline and near complete resolution of his left hemiparesis.

Some description of this patient's condition and course were included in a prior report. ${ }^{52}$ Further details of this patient's cerebral angiogram before and after treatment, pre- and postintervention neurological condition, and MRI findings are included here to increase comparability between multiple patients exhibiting the same symptoms and etiology.

\section{Review of 19 Cases of dAVF-Induced Thalamic Dementia}

Using multiple electronic databases (PubMed, Ovid, and EBSCO), a comprehensive review of the international literature (case reports, series, and reviews) was performed using the key phrases "dural arteriovenous fistula," "dAVF," "arteriovenous malformation," "thalamic dementia," "progressive dementia," "cortical venous drainage," "cortical venous hypertension," "bithalamic edema," and "bilateral thalamic edema." Bibliographies of relevant publications were examined to identify additional cases. Through this comprehensive search, 15 previously published cases of dAVF-induced thalamic dementia were identified for comparison with our 4 cases. Characteristics of these 19 cases are compared in Tables 2 and 3.

\section{Demographics and Presentation}

Dural AVF-inducted thalamic dementia is almost exclusively seen in men (18 of 19; 95\%) and is most common in the 5th-7th decades of life (mean age $60 \pm 10$ years; range 43-77 years). All patients (19 of 19; 100\%) presented with progressive cognitive dysfunction that included deficits in executive function, attention, memory, and disorientation. Fourteen of 19 patients (74\%) had additional neurological deficits including ataxia (5 of 19;26\%), aphasia (5 of 19; 26\%), confabulation (3 of 19; 16\%), hemiparesis ( 1 of $19 ; 5 \%)$, third cranial nerve palsy ( 1 of $19 ; 5 \%)$, upper-extremity tremor ( 1 of $19 ; 5 \%)$, myoclonus ( 1 of 19 ; 

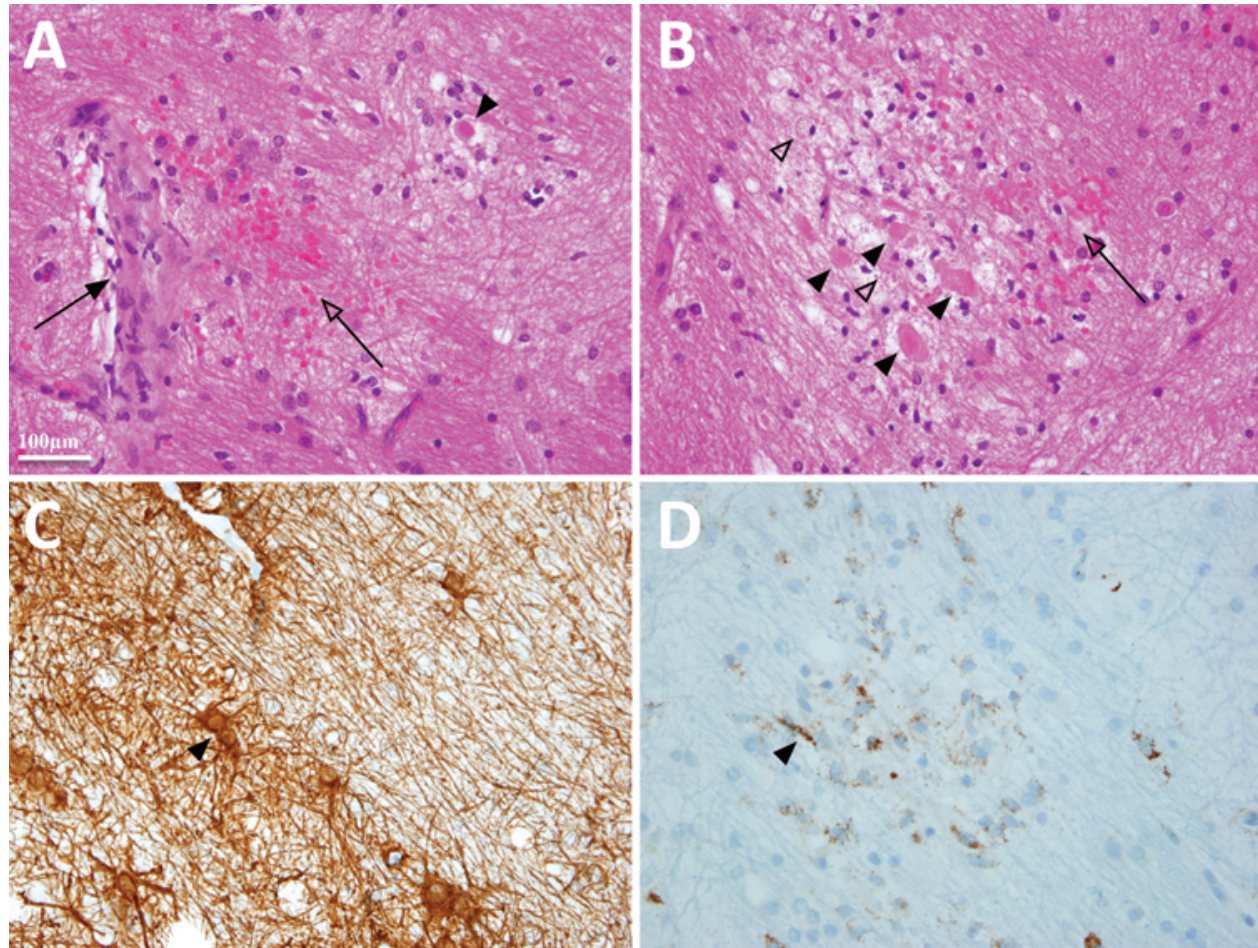

FIG. 5. Case 3. Histopathology. A and B: H \& E biopsy sections at medium power. Intermixed white and gray matter with reactive gliosis and prominent small vessels with reactive endothelium (solid arrow, A), occasional acute petechial hemorrhages (open arrow, A), focal microlesions with foamy macrophages (open arrowheads, B), numerous neuroaxonal spheroids (closed arrowheads, B), and rare nuclear pyknosis/karyorrhexis (open arrow, B). C and D: Immunohistochemistry at medium power. Staining for glial fibrillary acid protein (GFAP) demonstrated reactive astrocytes (arrowhead, C). Staining for CD68 showed microglia and macrophages surrounding vessels in focal microlesions (arrowhead, D). Figure is available in color online only.

$5 \%)$, and incontinence (1 of 19; 5\%). Some patients had more than 1 additional neurological deficit. The mean duration of symptoms at the time of angiographic diagnosis was 87 days (range 3 days to 18 months).

\section{Neuroimaging}

Pretreatment $C T$ and MRI. Head CT results were reported in 10 of 19 cases (53\%), 4 of which included contrast (Table 2). Five pretreatment CT scans (5 of 10; 50\%) demonstrated bithalamic hypoattenuation indicating edema. All CT scans in which contrast was given demonstrated enhancement (4 of $4 ; 100 \%)$. One CT scan (1 of $10 ; 10 \%)$ also demonstrated petechial hemorrhages. Pretreatment brain MRI results were reported in 17 of 19 cases $(89 \%), 16$ of which included gadolinium administration (Table 2). Bithalamic T2/FLAIR hyperintensities indicating edema were noted in all cases $(17$ of $17 ; 100 \%)$, 8 with symmetric edema and 9 with asymmetrical edema. Four MR images (4 of 17; 24\%) showed edema extending beyond the thalami (cortex, splenium, basal ganglia, or internal capsule). Ten scans (10 of 16; 62\%) demonstrated gadolinium enhancement, which was typically bilateral, mild, and patchy, though occasionally appeared avid and homogeneous. No MRI scan (0 of 17; $0 \%$ ) demonstrated any significant thalamic diffusion restriction.

Pretreatment Catheter Angiography. The majority of dAVFs producing thalamic dementia are located near the tentorial edge (14 of 19; 74\%), though some were located more peripherally. These locations included near the torcular herophili ( 1 of $19 ; 5 \%$ ), the transverse sinus ( 1 of 19 ; $5 \%$ ), the transverse-sigmoid sinus junction (1 of $19 ; 5 \%)$, a cerebral parasagittal sinus near the vertex (1 of $19 ; 5 \%)$, and near a persistent posterior falcine sinus (1 of $19 ; 5 \%$ ) (Table 3). Reflux through the vein of Galen was angiographically demonstrated in all 19 cases, though venous routes to the vein of Galen were variable. Fourteen fistulas (14 of $19 ; 74 \%)$ were associated with one or more thrombosed sinuses ( 9 straight sinuses, 3 sigmoid sinuses, 2 transverse sinuses, and 1 superior sagittal sinus). All 19 dAVFs were located posteriorly: supratentorial, tentorial, or infratentorial. Arterial supply was often derived from multiple vessels (13 of 19; 68\%). Regardless of nidus location, feeder vessels were most frequently derived from a middle meningeal artery (47\%), posterior meningeal artery (37\%), and/or occipital artery (37\%).

Pretreatment Metabolic and Perfusion Imaging. Five of the 19 patients underwent cerebral emission imaging (3 SPECT, 1 Xenon CT, and 1 PET), and 1 received MR spectroscopy. ${ }^{32,73,76-78}$ Bithalamic hypoperfusion (4 of 4; $100 \%$ ) and bithalamic congestion (2 of $2 ; 100 \%)$ were found each time these investigations were performed. PET results demonstrated bithalamic increase in fluorodeoxyglucose uptake in the single patient who underwent (Case 3). MR spectroscopy was also performed in a single patient and demonstrated bithalamic decrease in $\mathrm{N}$-acetylaspartate, increase in choline, and increase in lactate. ${ }^{73}$ 
TABLE 2. Published cases of dAVF-induced thalamic dementia syndrome: clinical characteristics

\begin{tabular}{|c|c|c|c|c|c|}
\hline Authors \& Year & Age (yrs), Sex & Presentation & Imaging Findings & Treatment & Outcome \\
\hline Nakada et al., 1985 & $63, \mathrm{M}$ & $\mathrm{RPD}$, ataxia & BTE by CT & Surgery & Death \\
\hline Ito et al., 1995 & $49, \mathrm{M}$ & $\begin{array}{l}\text { RPD, ataxia, } \\
\text { aphasia }\end{array}$ & $\begin{array}{l}\text { BTE by CT/MRI; bilthalamic vas- } \\
\text { cular congestion by SPECT }\end{array}$ & $\begin{array}{l}\text { TAE followed } \\
\text { by surgery }\end{array}$ & Symptomatic/radiographic resolution \\
\hline Greenough et al., 1999 & $62, \mathrm{M}$ & RPD, ataxia & BTE by MRI & Surgery & Symptomatic/radiographic improvement \\
\hline Tanaka et al., 1999 & $77, \mathrm{M}$ & RPD & $\begin{array}{l}\text { BTE by CT; bithalamic hypoper- } \\
\text { fusion by Xenon scan }\end{array}$ & Multiple TAEs & $\begin{array}{l}\text { Symptomatic/radiographic near resolu- } \\
\text { tion }\end{array}$ \\
\hline Bernstein et al., 2003 & $69, \mathrm{M}$ & RPD & Normal CT & TAE & Symptomatic/radiographic improvement \\
\hline Tamamoto et al., 2003 & $67, \mathrm{~F}$ & $\begin{array}{l}\text { RPD, inconti- } \\
\text { nence }\end{array}$ & $\begin{array}{l}\text { BTE by CT/MRI; bilthalamic vas- } \\
\text { cular congestion by SPECT }\end{array}$ & TAE & Symptomatic/radiographic improvement \\
\hline Tominaga et al., 2003 & $73, \mathrm{M}$ & RPD, ataxia & $\begin{array}{l}\text { BTE by MRI; bilthalamic vascu- } \\
\text { lar congestion by SPECT }\end{array}$ & Surgery & $\begin{array}{l}\text { Symptomatic improvement, radiographic } \\
\text { resolution }\end{array}$ \\
\hline Gonçalves et al., 2008 & $43, M$ & RPD & BTE by MRI & TAE & Symptomatic/radiographic resolution \\
\hline Matsumura et al., 2008 & $73, \mathrm{M}$ & RPD & BTE by MRI & TAE & $\begin{array}{l}\text { Symptomatic improvement, radiographic } \\
\text { resolution }\end{array}$ \\
\hline Racine et al., 2008 & & RPD & BTE by MRI & $\begin{array}{l}\text { TAE followed } \\
\text { by surgery }\end{array}$ & $\begin{array}{l}\text { Symptomatic improvement, radiographic } \\
\text { resolution }\end{array}$ \\
\hline Wilson et al., 2008 & $48, \mathrm{M}$ & $\begin{array}{l}\text { RPD, aphasia, } \\
\text { ataxia }\end{array}$ & BTE by CT/MRI & TAE & Symptomatic/radiographic resolution \\
\hline Sugrue et al., 2009 & $51, \mathrm{M}$ & RPD & BTE by MRI & TAE & $\begin{array}{l}\text { Symptomatic resolution, radiographic } \\
\text { improvement }\end{array}$ \\
\hline Yamamoto et al., 2010 & $51, \mathrm{M}$ & RPD & BTE by MRI & TAE & $\begin{array}{l}\text { Symptomatic improvement, radiographic } \\
\text { resolution }\end{array}$ \\
\hline Geraldes et al., 2011 & $64, \mathrm{M}$ & RPD, ataxia & BTE by MRI & TAE & $\begin{array}{l}\text { Symptomatic improvement, radiographic } \\
\text { resolution }\end{array}$ \\
\hline Santillan et al., 2011 & $50, \mathrm{M}$ & RPD & BTE by CT/MRI & TAE & Symptomatic/radiographic resolution \\
\hline Present study & $53, \mathrm{M}$ & RPD, aphasia & BTE by MRI & TAE & $\begin{array}{l}\text { Symptomatic improvement, radiographic } \\
\text { resolution }\end{array}$ \\
\hline Present study & $59, \mathrm{M}$ & RPD, aphasia & BTE by MRI & TVE & Death from unrelated medical condition \\
\hline Present study & $60, M$ & RPD & BTE by MRI & $\begin{array}{l}\text { TAE followed } \\
\text { by surgery }\end{array}$ & Symptomatic/radiographic resolution \\
\hline Present study & $71, \mathrm{M}$ & $\begin{array}{l}\mathrm{RPD} \text {, hemipa- } \\
\text { resis }\end{array}$ & BTE by MRI & $\begin{array}{l}\text { TAE followed } \\
\text { by surgery }\end{array}$ & $\begin{array}{l}\text { Symptomatic improvement, radiographic } \\
\text { resolution }\end{array}$ \\
\hline
\end{tabular}

BTE = bithalamic edema; OCSL = open craniotomy and surgical ligation; RPD = rapidly progressive dementia; TAE = transarterial embolization; TVE = transvenous embolization.

Posttreatment Imaging. All but one case reported posttreatment imaging findings. Fifteen of the 19 cases reported posttreatment catheter angiography and 5 of these were performed in delayed fashion. Eight of the 10 immediate posttreatment angiograms demonstrated dAVF obliteration $(8$ of $10 ; 80 \%)$. The remaining 2 showed dramatic fistula flow reductions. ${ }^{5,77}$ All 5 delayed angiograms showed no evidence of dAVF recurrence (5 of $5 ; 100 \%)$. Three of the 19 cases reported posttreatment CT imaging, 2 of which showed resolution of bithalamic hypoattenuation (2 of 3;67\%) and the other demonstrated dramatic improvement ( 1 of $3 ; 33 \%)$. Posttreatment MRI results were available for 13 of 19 cases (68\%). Bithalamic T2 hyperintensities resolved in all cases $(13$ of $13 ; 100 \%)$. Bithalamic enhancement resolved in all cases that reported pre- and posttreatment MRI with gadolinium administration (6 of $6 ; 100 \%$ ). Of the 3 cases reporting both pre- and posttreatment perfusion imaging, all demonstrated cerebral blood flow normalization (3 of $3 ; 100 \%)$. In general, posttreat- ment imaging revealed dramatic improvement or complete resolution of pretreatment abnormalities.

\section{Delays in Diagnosis/Treatment}

A delay in diagnosis and/or treatment of the offending dAVF was specifically noted in 4 of the 19 cases (21\%)-3 from the published literature ${ }^{21,53,73}$ and 1 from the present series (Case 3). In 3 of these 4 cases (including our Case 3 ), precise time data were provided; ${ }^{21,53}$ the average delay from presentation to angiographic diagnosis was 23 days. In addition, treatment following angiographic diagnosis was delayed further in one of these cases, as the lesion was initially felt to be incidental. ${ }^{53}$ Finally, 2 patients (including our Case 3) underwent invasive stereotactic biopsy prior to catheter angiography ${ }^{73}$ - both of which were nondiagnostic and one led to an asymptomatic thalamic hemorrhage (in our Case 3).

In the first case of delay, the initial discovery of the 
TABLE 3. Published cases of dAVF-induced thalamic dementia syndrome: angiographic findings

\begin{tabular}{|c|c|c|c|c|}
\hline Authors \& Year & $\begin{array}{l}\text { Mod. Borden-Shucart } \\
\text { Grade }\end{array}$ & Location & Arterial Feeders & Venous Outflow Pattern \\
\hline Nakada et al., 1985 & $3 S$ & Tentorial & MMA & Vein of Galen, thrombosed straight sinus \\
\hline Ito et al., 1995 & $2 S$ & Tentorial & Bilat PMA \& OccA & $\begin{array}{l}\text { Straight sinus, inferior sagittal sinus, vein of Galen, } \\
\text { basal vein of Rosenthal }\end{array}$ \\
\hline Greenough et al., 1999 & Straight sinus & Tentorial & NA & $\begin{array}{l}\text { Vein of Galen, internal cerebral veins, thrombosed } \\
\text { straight sinus }\end{array}$ \\
\hline Tanaka et al., 1999 & $2 S$ & Tentorial & $\begin{array}{l}\text { Bilat OccA, rt APA, } \\
\text { bilateral MMA }\end{array}$ & $\begin{array}{l}\text { Straight sinus, vein of Galen, thrombosed trans- } \\
\text { verse sinus }\end{array}$ \\
\hline Bernstein et al., 2003 & $3 S$ & Torcula & NA & $\begin{array}{l}\text { Vein of Galen, internal cerebral veins, thrombosed } \\
\text { sigmoid sinus }\end{array}$ \\
\hline Tamamoto et al., 2003 & $3 S$ & Tentorial & Lt STA, rt MMA, It PMA & $\begin{array}{l}\text { Vein of Galen, basal vein of Rosenthal, internal } \\
\text { cerebral veins }\end{array}$ \\
\hline Tominaga et al., 2003 & $2 S$ & $\begin{array}{l}\text { Transverse-sigmoid } \\
\text { sinus junction }\end{array}$ & Lt ECA, It PMA & $\begin{array}{l}\text { Straight sinus, vein of Galen, thrombosed sigmoid } \\
\text { sinus }\end{array}$ \\
\hline Gonçalves et al., 2008 & $2 S$ & Tentorial & $\begin{array}{l}\text { Meningeal branches of rt } \\
\text { ICA, rt ECA, rt OccA }\end{array}$ & $\begin{array}{l}\text { Straight sinus, vein of Galen, internal cerebral } \\
\text { veins }\end{array}$ \\
\hline Matsumura et al., 2008 & $2 S$ & Tentorial & NA & Vein of Galen \\
\hline Racine et al., 2008 & $3 S$ & Torcula & Rt OccA, It PMA & Vein of Galen, thrombosed straight sinus \\
\hline Wilson et al., 2008 & $2 S$ & Tentorial & NA & $\begin{array}{l}\text { Straight sinus, vein of Galen, thrombosed sigmoid } \\
\text { sinus }\end{array}$ \\
\hline Sugrue et al., 2009 & $2 S$ & $\begin{array}{l}\text { Superior sagittal } \\
\text { Sinus }\end{array}$ & $\begin{array}{l}\text { Bilat MMA, PMA, mar- } \\
\text { ginal TentA }\end{array}$ & $\begin{array}{l}\text { Posterior falcine sinus, vein of Galen, basal vein of } \\
\text { Rosenthal, internal cerebral veins, thrombosed } \\
\text { straight sinus }\end{array}$ \\
\hline Yamamoto et al., 2010 & $3 S$ & Tentorial & Bilat ICA & $\begin{array}{l}\text { Vein of Galen, internal cerebral vein, thrombosed } \\
\text { straight sinus }\end{array}$ \\
\hline Geraldes et al., 2011 & $2 S$ & Torcula & Bilat PMA, rt MMA & $\begin{array}{l}\text { Vein of Galen, thrombosed transverse and sagittal } \\
\text { sinus }\end{array}$ \\
\hline Santillan et al., 2011 & $3 S$ & Tentorial & Medial TentA, MMA & $\begin{array}{l}\text { Vein of Galen, basal vein of Rosenthal, internal } \\
\text { cerebral veins, thrombosed straight sinus }\end{array}$ \\
\hline Present study & $2 S$ & Tentorial & $\begin{array}{l}\text { Bilat MMA, inferolateral } \\
\text { trunks of ICAs }\end{array}$ & $\begin{array}{l}\text { Straight sinus, vein of Galen, internal cerebral } \\
\text { veins }\end{array}$ \\
\hline Present study & $3 S$ & Tentorial & Lt OccA, bilat PMA & $\begin{array}{l}\text { Superior vermian vein, vein of Galen, internal ce- } \\
\text { rebral veins, partially thrombosed straight sinus }\end{array}$ \\
\hline Present study & $3 S$ & Torcula & Rt OccA & Vein of Galen, internal cerebral veins \\
\hline Present study & $3 S$ & Torcula & Bilat OccA, bilat MMA & $\begin{array}{l}\text { Superior vermian vein, vein of Galen, thrombosed } \\
\text { straight sinus }\end{array}$ \\
\hline
\end{tabular}

$\mathrm{APA}=$ ascending pharyngeal artery; $\mathrm{ECA}=$ external carotid artery; $\mathrm{MMA}=$ middle meningeal artery; $\mathrm{NA}=$ not available; OccA = occipital artery; $\mathrm{PMA}=$ posterior meningeal artery; STA = superficial temporal artery; Tent $A=$ tentorial artery.

dAVF via catheter angiography occurred relatively early in the course of the illness but was considered an incidental finding. ${ }^{53}$ As the patient's cognitive function continued to deteriorate (eventually progressing to coma), repeat head CT was performed, demonstrating low attenuation of the diencephalon. The diagnosis of dAVF-induced thalamic dementia was then made, and the dAVF underwent surgical obliteration. Unfortunately, the patient remained in a coma after surgery and died 21 days later. In the second case of delay, a lack of white matter changes on brain MRI initially altered the authors' differential diagnosis away from dAVF. ${ }^{73}$ During this delay, the patient suffered a capsulolenticular hematoma, and his neurological condition progressed to coma. Nine days later, catheter angiography was performed, revealing the offending dAVF. The patient underwent embolization of the dAVF, and his dementia slowly improved over 3 months with resolution of the associated myoclonus but not the hemiparesis. In the third case of delay, a malignant neoplasm was suspected, in part due to gadolinium enhancement noted on brain MRI. ${ }^{21}$ The patient underwent a stereotactic biopsy that was nondiagnostic, which prompted reevaluation of the differential diagnosis, performance of catheter angiography, and endovascular treatment of the offending dAVF. The patient's neurological condition fully resolved within 4 months. In the fourth case of delay (Case 3 of the present series), a malignant neoplasm was suspected, in part due to gadolinium enhancement noted on brain MRI. The patient underwent stereotactic biopsy that was nondiagnostic and complicated by an asymptomatic thalamic hemorrhage. Six weeks 
of vitamin supplementation for the presumed diagnosis of Wernicke's encephalopathy ensued. Due to further deterioration in the patient's cognitive status, catheter angiography was performed, which identified the offending dAVF. The patient underwent combined endovascular and surgical obliteration of the dAVF, and his neurological condition improved dramatically over the ensuing 3 months.

\section{Treatment}

All 19 patients underwent dAVF treatment with surgery, endovascular therapy, or a combination. Sixteen of the 19 patients $(84 \%)$ were treated initially with endovascular embolization, 15 via a transarterial approach, and 2 via a transvenous approach; 2 approaches were performed in 1 patient in a single procedure. Eleven of these patients (11 of $19 ; 69 \%$ ) had elimination of the CVD-8 with complete obliteration of the $\mathrm{dAVF}$ and 3 with obliteration of the CVD alone. One patient required a second endovascular procedure with subsequent complete obliteration of the dAVF. Therefore, overall success (defined as angiographic elimination of the CVD) was achieved in $75 \%$ (12 of 16) of patients undergoing endovascular embolization. No procedural complications were reported.

The remaining 4 patients who initially underwent endovascular therapy required surgical intervention, all of which led to complete radiographic obliteration on postoperative imaging. Another 3 cases were treated exclusively with open surgery. One of these cases noted successful intraoperative obliteration of the dAVF, but did not report postoperative imaging findings. ${ }^{53}$ The other 2 cases documented complete radiographic obliteration of the dAVF on postoperative imaging. ${ }^{23,78}$ Therefore, the overall cure rate for surgically treated dAVFs was $100 \%$ (7 of 7; 6 documented by postoperative imaging, 1 documented by surgeon impression). One surgical complication was reported in which hydrocephalus developed after surgery requiring shunt treatment. ${ }^{23}$

\section{Long-Term Patient Outcome}

Eighteen of 19 cases had long-term patient outcomes reported. Of these, 6 patients (6 of 18; 33\%) experienced complete radiographic and functional recovery following dAVF obliteration, all within 6 months of their treatment. Ten patients (10 of $18 ; 55 \%$ ) experienced significant but incomplete improvement in their dementia and other neurological deficits in late follow-up (typically months from treatment). One patient ( 1 of $18 ; 6 \%$ - the earliest reported case) died in the hospital 21 days after surgery-likely the result of delayed treatment. ${ }^{53}$ One patient (1 of $18 ; 6 \%-$ Case 2 in the present series) died of an unrelated cause (myocardial infarction) 3 months after surgery, although his dementia had been steadily improving since dAVF treatment. Most recoveries began soon after dAVF obliteration, though maximal recovery often took weeks to months. Only 4 cases reported on follow-up catheter angiography, all of which demonstrated continued obliteration of the treated dAVF. ${ }^{5,65,73,86}$ No recurrence of dAVF-related symptoms was reported in any of the 18 cases.

\section{Discussion}

The incidence of dementia as a presenting symptom of high-grade dAVFs has been reported to be as low $0 \%{ }^{71}$ and as high as $11 \% .^{72}$ The manner by which this occurs is fairly well established-arterialized venous reflux from the fistula produces regional venous congestion and parenchymal edema, leading to functional compromise of the affected brain regions. ${ }^{79}$ Two types of dAVF-induced dementia have been described, each of which has its own distinct clinical and neuroimaging characteristics. Cortical dementia due to dAVF is characterized by rapidly progressive cognitive dysfunction including impairments in verbal fluency and language comprehension, apraxia, visuospatial discordance, and memory dysfunction that is frequently accompanied by focal cortical deficits including hemiparesis, somatic sensory disturbances, aphasia, alexia, and/or visual disturbances. . $3,16,18,28,31,36,37,41,54,61,69,80,81,84,85,87,89$ These symptoms are associated with widespread and/or multilobar hyperintensities on FLAIR and T2-weighted imaging. 31,41,54,82 Thalamic dementia due to dAVF is characterized by rapidly progressive cognitive dysfunction including disorientation, executive dysfunction, attention deficits, memory impairment, confabulation and disinhibition. Hereto, additional neurological deficits are frequent but relate to dysfunction of the thalamus itself (e.g., thalamic aphasia or ataxia) or nearby structures (e.g., internal capsule leading to hemiparesis, third cranial nerve leading to diplopia). These symptoms are accompanied by a more focused profile of hyperintensities on FLAIR and T2-weighted imaging primarily involving the bilateral thalami. ${ }^{21-23,32,34,48,49,53,62,65,73,76-78,86,88}$

\section{Dural AVF-Induced Thalamic Dementia: Presentation, Imaging, Treatment, and Outcome}

Dural AVF-induced syndrome occurs almost exclusively in men in their 5th-7th decades of life, typically without prior history of neurological trauma. The most common symptoms of this syndrome are deficits in attention, memory, executive functioning, and disorientation. Other symptoms are variably present, including ataxia, aphasia, amnesia, and/or hemiparesis. The rapidity of onset is typically weeks to a few months (mean duration in our review 87 days). CT/MRI workup invariably demonstrates bilateral thalamic edema, not uncommonly associated with patchy enhancement and occasionally petechial hemorrhage. Diffusion restriction is not seen. Obvious vascular abnormalities such as dilated deep venous structures including the vein of Galen are often not appreciated on standard axial imaging; therefore, dedicated vascular imaging must be obtained to secure the diagnosis.

Most offending dAVFs are located at the tentorial edge, but more peripheral lesions with venous drainage that ultimately involves the vein of Galen can also produce this syndrome (e.g., at the torcular herophili). Once identified, dAVF treatment-either via endovascular or surgical means-carries low risk and is highly effective at disconnecting the CVD, the portion of the dAVF that is responsible for the dementia syndrome. Often complete radiographic obliteration of dAVF is achieved. In our review of the 16 cases treated with endovascular therapy, no procedural complications occurred, and CVD obliteration was achieved $75 \%$ of the time. In our review of the 7 cases treated with surgical therapy, one procedural 
complication occurred (postoperative hydrocephalus requiring a shunt) and CVD obliteration was achieved $100 \%$ of the time ( 6 documented by postoperative imaging; 1 by surgeon impression). Both endovascular and surgical therapies are therefore excellent options, with decision making regarding which approach to take involving an assessment of the following factors: available endovascular access to the dAVF and CVD, age and comorbidities of the patient, and patient/family preference regarding level of invasiveness of the procedure versus procedural success rate. Symptom resolution invariably begins within days of elimination of the CVD with maximal neurological recovery being achieved over the ensuing months. In our review of the 18 cases reporting long-term clinical outcome, $33 \%$ of patients experienced complete resolution of their dementia symptoms, 55\% experienced significant but incomplete resolution of their dementia symptoms, $6 \%$ died of unrelated causes, and $6 \%$ died due to progressive dAVF-induced symptoms. The latter was the first reported case of dAVF-induced thalamic dementia and included a substantial delay in initiating treatment. No recurrences of the offending fistula or the dementia symptoms have been reported, though most studies did not include follow-up vascular imaging to detect an asymptomatic recurrence.

Thalamic Dementia Syndrome: Differential Diagnosis and Workup

Dural AVFs are one of a number of conditions that can cause thalamic dementia. Classically, this term was used describe the constellation of cognitive symptoms present in patients who develop thalamic ischemic stroke-especially those with bilateral thalamic involvement. ${ }^{12,38,40,59,67,74,75}$ These symptoms can manifest in several particular patterns owing to the various functions performed by the different thalamic nuclei. In the context of dAVFs, the hallmarks of the symptom complex-deficits in executive function, memory, learning, attention, disinhibition, and confabulation-correspond best to the anteromedial and central thalamic regions. ${ }^{12,20,21,38,43,51,56,59,62,65,74,85}$ Sensory and motor symptoms typically ascribed to posterolateral and inferior thalamic distributions tend to be uncommon or absent in patients with dAVFs. The term thalamic dementia syndrome has also been applied to patients having similar symptoms related to other pathological conditions affecting the thalami, including deep venous system thrombosis, bilateral diencephalic tumors, viral and prion diseases, osmotic myelinolysis, and toxic insults (see Table 4).

Distinguishing these various etiologies starts with a thorough history. Symptom onset can separate etiologies in many cases, with acute onset (minutes) suggesting arterial infarction, subacute onset (days to weeks) suggesting $\mathrm{dAVF}$, deep venous thrombosis, or infection, and chronic (months or years) suggesting tumors or prion disease. A variable or recurring presentation would suggest a toxic or metabolic etiology. Other clinical clues that may help delineate the underlying condition include accompanying presenting symptoms (fever for infection) and medical history (oral birth control for hypercoaguable deep venous thrombosis; alcohol abuse for Wernicke encephalopathy; recent hyponatremia for osmotic myelinolysis; recent vector exposure for West Nile and Japanese encephalitis). Any of these presentations in conjunction with rapidly progress- ing dementia should prompt neuroimaging with MRI to further assist in differentiating the possible causes.

MRI can be of great value in helping to determine the underlying etiology of the thalamic dementia syndrome. A comparison of the radiographic findings for the various conditions that cause thalamic dementia is provided in Table 4. The presence of diffusion restriction most strongly suggests arterial stroke, toxicity, infection, or, to a lesser degree, lymphoma or deep venous thrombosis. . $2,4,25-27,35,39,42,45,50,57,60,70,90$ Conversely, diffusion restriction has not been found in patients with dAVF-induced thalamic dementia. Strong gadolinium enhancement is most consistent with a high-grade neoplasm; ${ }^{26,27,58}$ however, other conditions including dAVFs can also have some degree of gadolinium enhancement. ${ }^{62,76,77}$ Therefore, vigilance is required when considering the diagnosis of neoplasm, and additional diagnostic tests are often indicated prior to proceeding with stereotactic brain biopsy. The distribution of T2/FLAIR signal hyperintensities may also offer clues to the diagnosis. Arterial strokes will follow arterial distributions, while neoplasms are more inclined to circumscribe tissue planes. . $^{2,11,15,27,45,58,70}$ Deep AVFs and deep venous thromboses produce T2/FLAIR hyperintensities centered within the bilateral anteromedial thalamic regions, though extensions beyond the thalami are reported in a significant number of cases. $5,18,21,22,76,77$

In many instances, a definitive diagnosis for the thalamic dementia syndrome cannot be reached after history, physical examination, and MRI. Due to the overlapping nature of the signal characteristics associated with many of the causative conditions, we advocate that patients receive a catheter angiogram prior to an invasive diagnostic procedure (e.g., stereotactic biopsy) or prolonged medical therapy (e.g., vitamin supplementation for suspected Wernicke encephalopathy) because of its ability to definitively delineate a vascular lesion from other etiologies. Although catheter angiography is presently the only way to conclusively diagnose this condition, some progress has been made with noninvasive vascular imaging modalities of dAVFs. Coley et al. have reported that a new technique called MR digital subtraction angiography (MR-DSA) is capable of producing time-resolved dynamic vascular imaging of the brain that was useful for the initial confirmation and subsequent monitoring of dAVFs, though they admit that catheter angiography is still necessary for detailed anatomical evaluation. ${ }^{14}$ Hori et al. evaluated the utility of time-resolved 3D MR digital subtraction angiography (Time-SLIP 3D MRDSA) for assessment of dAVFs. ${ }^{29}$ In comparing intraarterial DSA to this technique, which does not require injection of contrast material, they reported accurate diagnosis and evaluations of hemodynamic information relating to $6 \mathrm{dAVFs}$. Jagadeesan et al. documented that MR susceptibility-weighted imaging is highly accurate for the detection of arteriovenous shunting in arteriovenous malformations of the brain, but this technique has yet to be applied to dAVFs themselves. ${ }^{33}$

\section{Conclusions}

Our report emphasizes that unexplained rapidly progressing dementia, particularly in middle- to older-aged 
TABLE 4. Differential diagnosis for patients with rapidly progressive dementia and bithalamic edema

\begin{tabular}{|c|c|c|c|c|}
\hline Diagnosis & T1-Weighted & T1-Weighted w/ Gadolinium & T2/FLAIR & DWI/ADC \\
\hline High-grade glioma* & Hypointense & $\begin{array}{l}\text { Irregular or rim-enhancement, } \\
\text { central hypointensity (necrosis) }\end{array}$ & $\begin{array}{l}\text { Rim hyperintense, often cen- } \\
\text { tral hypo- or isointense }\end{array}$ & $\begin{array}{l}\text { Hyperintense DWI, hypoin- } \\
\text { tense ADC }\end{array}$ \\
\hline Lymphoma† & Hypo- or isointense & $\begin{array}{l}\text { Enhancement ( } 90 \% \text { homogeneous } \\
\text { in non-AIDS cases, } 75 \% \text { ring- } \\
\text { enhancement in AIDS cases) }\end{array}$ & Iso- or hyperintense & $\begin{array}{l}\text { Hyperintense DWI, hypoin- } \\
\text { tense ADC }\end{array}$ \\
\hline $\begin{array}{l}\text { Wernicke's encephalopa- } \\
\text { thy } \ddagger\end{array}$ & Hypointense & Variable enhancement & $\begin{array}{l}\text { Symmetric periaqueductal } \\
\text { and paraventricular hyper- } \\
\text { intensities }\end{array}$ & $\begin{array}{l}\text { Weakly to moderately hy- } \\
\text { perintense DWI, variable } \\
\text { ADC intensities }\end{array}$ \\
\hline $\begin{array}{l}\text { Carbon monoxide poison- } \\
\text { ing§ }\end{array}$ & Hypointense & Patchy enhancement & $\begin{array}{l}\text { Hyperintense, especially GP } \\
\text { and cortical white matter }\end{array}$ & $\begin{array}{l}\text { Hyperintense DWI, hypoin- } \\
\text { tense ADC }\end{array}$ \\
\hline Hepatic encephalopathy & $\begin{array}{l}\text { Hyperintense, espe- } \\
\text { cially GP (manga- } \\
\text { nese) }\end{array}$ & No enhancement & $\begin{array}{l}\text { Patchy white matter hyperin- } \\
\text { tensities, may require fast } \\
\text { FLAIR to detect }\end{array}$ & $\begin{array}{l}\text { Hyperintense DWI, hypoin- } \\
\text { tense ADC }\end{array}$ \\
\hline Osmotic myelinolysis ${ }^{* *}$ & Patchy hypointensities & Rare enhancement & $\begin{array}{l}\text { Hyperintense, especially } \\
\text { central pons }\end{array}$ & $\begin{array}{l}\text { Hyperintense DWI, hypoin- } \\
\text { tense ADC }\end{array}$ \\
\hline $\begin{array}{l}\text { West Nile Virus/Japanese } \\
\text { encephalitis** }\end{array}$ & Hypointense & Variable enhancement & $\begin{array}{l}\text { Hyperintense, BG, midbrain } \\
\text { \& sulci (leptomeningeal } \\
\text { inflammation) }\end{array}$ & $\begin{array}{l}\text { Hyperintense DWI (pos- } \\
\text { terior limb of internal } \\
\text { capsule, corona radiata), } \\
\text { ADC hypointense }\end{array}$ \\
\hline Prion disease ${ }^{* *}$ & Hypointense & No enhancement & $\begin{array}{l}\text { Hyperintense, especially } \\
\text { pulvinar (pulvinar sign in } \\
\text { variant CJD) }\end{array}$ & $\begin{array}{r}\text { Hyperintense DWI, BG and } \\
\text { cortex, hypointense ADC }\end{array}$ \\
\hline $\begin{array}{l}\text { Arterial infarction (bitha- } \\
\quad \text { lamic infarction; top of } \\
\text { the basilar syndrome) }^{* *}\end{array}$ & Hypointense & Variable enhancement & $\begin{array}{l}\text { Hyperintense, BG \& mid- } \\
\text { brain (“V” sign) }\end{array}$ & $\begin{array}{l}\text { Hyperintense DWI, hypoin- } \\
\text { tense ADC }\end{array}$ \\
\hline $\begin{array}{l}\text { Deep venous system throm- } \\
\text { bosis (hypercoaguable; } \\
\text { sickle cell; idiopathic)** }\end{array}$ & $\begin{array}{l}\text { Hypointense thalami, } \\
\text { possible hyperinten- } \\
\text { sity (clot in sinus) }\end{array}$ & Patchy enhancement & Hyperintense & $\begin{array}{l}\text { Heterogeneously hyperin- } \\
\text { tense DWI, hypointense } \\
\text { ADC }\end{array}$ \\
\hline DAVF & Hypointense & Variable, patchy enhancement & $\begin{array}{l}\text { Hyperintense, possible } \\
\text { extension beyond thalami }\end{array}$ & Normal DWI \& ADC \\
\hline
\end{tabular}

$\mathrm{ADC}=$ apparent diffusion coefficient; $\mathrm{BG}$ = basal ganglia; $\mathrm{CJD}=$ Creutzfeldt-Jakob disease; $\mathrm{DWI}$ = diffusion-weighted imaging; $\mathrm{GP}=$ globus pallidus .

* References $27,45,58$, and 70 .

$\dagger$ References 26 and 70.

$\ddagger$ References $25,35,45,46,63,70,83,92$, and 93 .

$\S$ References 57 and 70 .

If References 41, 45, 70, and 90.

${ }^{* *}$ Reference 70.

men, should be evaluated with MRI and likely also catheter angiography. MRI signal characteristics most consistent with dAVF are bilateral anteromedial thalamic hyperintensities on T2/FLAIR sequences without evidence for gadolinium enhancement, petechial hemorrhages, or restricted diffusion. However, variability in these signal characteristics exist, and extension of the T2-weighted/ FLAIR hyperintensities beyond the thalami, gadolinium enhancement (typically mild to moderate in intensity and patchy in appearance), and petechial hemorrhage has been reported in the context of dAVF-induced thalamic dementia. Therefore, we recommend evaluation with catheter angiography prior to stereotactic brain biopsy (which likely carries increased risk in dAVF patients due to the hyperemic nature of the involved tissue) and/or prolonged medical treatment (which delays dAVF treatment and subject patients to the potential of rapidly progressive symptoms) unless a definitive diagnosis of a nonvascular etiology has been reached through other means. Once a dAVF is identified as the cause of the thalamic dementia syndrome, prompt treatment should be initiated, given that rapid neurological decline in the days following initial dAVF diagnosis has been reported in several cases. Treatment with either endovascular or surgical techniques carries a low risk of complications and is associated with a high degree of success, often leading to dramatic resolution of the presenting symptoms and resolution of the MRI abnormalities.

\section{References}

1. Abe T, Kojima K, Shoji H, Tanaka N, Fujimoto K, Uchida M, et al: Japanese encephalitis. J Magn Reson Imaging 8:755-761, 1998

2. Ameridou I, Spilioti M, Amoiridis G: Bithalamic infarcts: embolism of the top of basilar artery or deep cerebral venous thrombosis? Clin Neurol Neurosurg 106:345-347, 2004 
3. Awad IA, Little JR, Akarawi WP, Ahl J: Intracranial dural arteriovenous malformations: factors predisposing to an aggressive neurological course. J Neurosurg 72:839-850, 1990

4. Bell DA, Davis WL, Osborn AG, Harnsberger HR: Bithalamic hyperintensity on T2-weighted MR: vascular causes and evaluation with MR angiography. AJNR Am J Neuroradiol 15:893-899, 1994

5. Bernstein R, Dowd CF, Gress DR: Rapidly reversible dementia. Lancet 361:392, 2003

6. Borden JA, Wu JK, Shucart WA: Correction: dural arteriovenous fistulous malformations. J Neurosurg 82:705-706, 1995 (Erratum for J Neurosurg 82:166-179, 1995)

7. Borden JA, Wu JK, Shucart WA: A proposed classification for spinal and cranial dural arteriovenous fistulous malformations and implications for treatment. J Neurosurg 82:166179,1995

8. Brown RD Jr, Flemming KD, Meyer FB, Cloft HJ, Pollock BE, Link ML: Natural history, evaluation, and management of intracranial vascular malformations. Mayo Clin Proc 80:269-281, 2005

9. Brown RD Jr, Wiebers DO, Nichols DA: Intracranial dural arteriovenous fistulae: angiographic predictors of intracranial hemorrhage and clinical outcome in nonsurgical patients. J Neurosurg 81:531-538, 1994

10. Bulters DO, Mathad N, Culliford D, Millar J, Sparrow OC: The natural history of cranial dural arteriovenous fistulae with cortical venous reflux - the significance of venous ectasia. Neurosurgery 70:312-319, 2012

11. Carrera E, Michel P, Bogousslavsky J: Anteromedian, central, and posterolateral infarcts of the thalamus: three variant types. Stroke 35:2826-2831, 2004

12. Castaigne P, Lhermitte F, Buge A, Escourolle R, Hauw JJ, Lyon-Caen O: Paramedian thalamic and midbrain infarct: clinical and neuropathological study. Ann Neurol 10:127148, 1981

13. Chan HY, Cheng KM, Lo MW, Chan CM, Cheung YL: A treatable case of dementia--intracranial dural arteriovenous fistula. Hong Kong Med J 12:74-76, 2006

14. Coley SC, Romanowski CA, Hodgson TJ, Griffiths PD: Dural arteriovenous fistulae: noninvasive diagnosis with dynamic MR digital subtraction angiography. AJNR Am J Neuroradiol 23:404-407, 2002

15. Crawford SC, Digre KB, Palmer CA, Bell DA, Osborn AG: Thrombosis of the deep venous drainage of the brain in adults. Analysis of seven cases with review of the literature. Arch Neurol 52:1101-1108, 1995

16. Datta NN, Rehman SU, Kwok JC, Chan KY, Poon CY: Reversible dementia due to dural arteriovenous fistula: a simple surgical option. Neurosurg Rev 21:174-176, 1998

17. Davies MA, terBrugge K, Willinsky R, Coyne T, Saleh J, Wallace MC: The validity of classification for the clinical presentation of intracranial dural arteriovenous fistulas. J Neurosurg 85:830-837, 1996

18. Dehdashti AR, Matouk CC, terBrugge K, Wallace MC, Willinsky RA: Clues to dural arteriovenous fistulas in patients with progressive dementia. Can J Neurol Sci 37:532-534, 2010

19. Duffau H, Lopes M, Janosevic V, Sichez JP, Faillot T, Capelle $\mathrm{L}$, et al: Early rebleeding from intracranial dural arteriovenous fistulas: report of 20 cases and review of the literature. J Neurosurg 90:78-84, 1999

20. Fisher CM: Lacunar strokes and infarcts: a review. Neurology 32:871-876, 1982

21. Geraldes R, Albuquerque L, Ferro JM, Sousa R, Sequeira P, Campos J: Rapidly progressive cognitive impairment, ataxia, and myoclonus: an unusual presentation of a dural arteriovenous fistula. J Stroke Cerebrovasc Dis 21:619.e3-619.e5, 2012

22. Gonçalves MB, Maia O Jr, Correa JL, Siqueira SB, de Hol- anda Christoph D, Landeiro JA: Dural arteriovenous fistula presenting as thalamic dementia. Arq Neuropsiquiatr $\mathbf{6 6}$ (2A):264-267, 2008

23. Greenough GP, Mamourian A, Harbaugh RE: Venous hypertension associated with a posterior fossa dural arteriovenous fistula: another cause of bithalamic lesions on MR images. AJNR Am J Neuroradiol 20:145-147, 1999

24. Gross BA, Du R: The natural history of cerebral dural arteriovenous fistulae. Neurosurgery 71:594-603, 2012

25. Ha ND, Weon YC, Jang JC, Kang BS, Choi SH: Spectrum of MR imaging findings in Wernicke encephalopathy: are atypical areas of involvement only present in nonalcoholic patients? AJNR Am J Neuroradiol 33:1398-1402, 2012

26. Haldorsen IS, Espeland A, Larsson EM: Central nervous system lymphoma: characteristic findings on traditional and advanced imaging. AJNR Am J Neuroradiol 32:984-992, 2011

27. Hirano H, Yokoyama S, Nakayama M, Nagata S, Kuratsu $\mathrm{J}$ : Bilateral thalamic glioma: case report. Neuroradiology 42:732-734, 2000

28. Hirono N, Yamadori A, Komiyama M: Dural arteriovenous fistula: a cause of hypoperfusion-induced intellectual impairment. Eur Neurol 33:5-8, 1993

29. Hori M, Shiraga N, Watanabe Y, Aoki S, Isono S, Yui M, et al: Time-resolved three-dimensional magnetic resonance digital subtraction angiography without contrast material in the brain: Initial investigation. J Magn Reson Imaging 30:214-218, 2009

30. Houser OW, Baker HL Jr, Rhoton AL Jr, Okazaki H: Intracranial dural arteriovenous malformations. Radiology 105:55-64, 1972

31. Hurst RW, Bagley LJ, Galetta S, Glosser G, Lieberman AP, Trojanowski J, et al: Dementia resulting from dural arteriovenous fistulas: the pathologic findings of venous hypertensive encephalopathy. AJNR Am J Neuroradiol 19:1267-1273, 1998

32. Ito M, Sonokawa T, Mishina H, Sato K: Reversible dural arteriovenous malformation-induced venous ischemia as a cause of dementia: treatment by surgical occlusion of draining dural sinus: case report. Neurosurgery 37:1187-1192, 1995

33. Jagadeesan BD, Delgado Almandoz JE, Moran CJ, Benzinger TL: Accuracy of susceptibility-weighted imaging for the detection of arteriovenous shunting in vascular malformations of the brain. Stroke 42:87-92, 2011

34. Jaillard AS, Peres B, Hommel M: Neuropsychological features of dementia due to dural arteriovenous malformation. Cerebrovasc Dis 9:91-97, 1999

35. Jung YC, Chanraud S, Sullivan EV: Neuroimaging of Wernicke's encephalopathy and Korsakoff's syndrome. Neuropsychol Rev 22:170-180, 2012

36. Kai Y, Ito K, Kinjo T, Hokama Y, Nagamine H, Kushi S, et al: Reversibility of cognitive disorder after treatment of dural arteriovenous fistulae. Neuroradiology 51:731-739, 2009

37. Kajitani M, Yagura H, Kawahara M, Hirano M, Ueno S, Fujimoto K, et al: Treatable fluctuating Parkinsonism and dementia in a patient with a dural arteriovenous fistula. Mov Disord 22:437-439, 2007

38. Katz DI, Alexander MP, Mandell AM: Dementia following strokes in the mesencephalon and diencephalon. Arch Neurol 44:1127-1133, 1987

39. Kile SJ, Camilleri CC, Latchaw RE, Tharp BR: Bithalamic lesions of butane encephalopathy. Pediatr Neurol 35:439441,2006

40. Krolak-Salmon P, Montavont A, Hermier M, Milliery M, Vighetto A: Thalamic venous infarction as a cause of subacute dementia. Neurology 58:1689-1691, 2002

41. Kuroda S, Furukawa K, Shiga T, Ushikoshi S, Katoh C, Aoki T, et al: Pretreatment and posttreatment evaluation of hemo- 
dynamic and metabolic parameters in intracranial dural arteriovenous fistulae with cortical venous reflux. Neurosurgery 54:585-592, 2004

42. Lafitte F, Boukobza M, Guichard JP, Reizine D, Woimant F, Merland JJ: Deep cerebral venous thrombosis: imaging in eight cases. Neuroradiology 41:410-418, 1999

43. Lanna ME, Madeira DM, Alves G, Alves CE, Valente LE, Laks J, et al: Vascular dementia by thalamic strategic infarct. Arq Neuropsiquiatr 66:412-414, 2008

44. Lasjaunias P, Chiu M, terBrugge K, Tolia A, Hurth M, Bernstein M: Neurological manifestations of intracranial dural arteriovenous malformations. J Neurosurg 64:724-730, 1986

45. Linn J, Hoffmann LA, Danek A, Brückmann H: [Differential diagnosis of bilateral thalamic lesions.] Rofo 179:234-245, 2007 (Ger)

46. Liou KC, Kuo SF, Chen LA: Wernicke encephalopathy with atypical magnetic resonance imaging. Am J Emerg Med 30:2086.e1-2086.e3, 2012

47. Malik GM, Pearce JE, Ausman JI, Mehta B: Dural arteriovenous malformations and intracranial hemorrhage. Neurosurgery 15:332-339, 1984

48. Matsuda S, Waragai M, Shinotoh H, Takahashi N, Takagi K, Hattori T: Intracranial dural arteriovenous fistula (DAVF) presenting progressive dementia and parkinsonism. J Neurol Sci 165:43-47, 1999

49. Matsumura A, Oda M, Hozuki T, Imai T, Shimohama S: Dural arteriovenous fistula in a case of dementia with bithalamic MR lesions. Neurology 71:1553, 2008

50. Misra UK, Kalita J, Phadke RV, Wadwekar V, Boruah DK, Srivastava A, et al: Usefulness of various MRI sequences in the diagnosis of viral encephalitis. Acta Trop 116:206-211, 2010

51. Mitchell AS, Dalrymple-Alford JC: Lateral and anterior thalamic lesions impair independent memory systems. Learn Mem 13:388-396, 2006

52. Morparia N, Miller G, Rabinstein A, Lanzino G, Kumar N: Cognitive decline and hypersomnolence: thalamic manifestations of a tentorial dural arteriovenous fistula (dAVF). Neurocrit Care 17:429-433, 2012

53. Nakada T, Kwee IL, Ellis WG, St John JN: Subacute diencephalic necrosis and dural arteriovenous malformation. Neurosurgery 17:653-656, 1985

54. Nencini P, Inzitari D, Gibbs J, Mangiafico S: Dementia with leucoaraiosis and dural arteriovenous malformation: clinical and PET case study. J Neurol Neurosurg Psychiatry 56:929-931, 1993

55. Newton $\mathrm{TH}$, Cronqvist $\mathrm{S}$ : Involvement of dural arteries in intracranial arteriovenous malformations. Radiology 93:1071-1078, 1969

56. Nishio Y, Hashimoto M, Ishii K, Mori E: Neuroanatomy of a neurobehavioral disturbance in the left anterior thalamic infarction. J Neurol Neurosurg Psychiatry 82:1195-1200, 2011

57. O’Donnell P, Buxton PJ, Pitkin A, Jarvis LJ: The magnetic resonance imaging appearances of the brain in acute carbon monoxide poisoning. Clin Radiol 55:273-280, 2000

58. Partlow GD, del Carpio-O'Donovan R, Melanson D, Peters TM: Bilateral thalamic glioma: review of eight cases with personality change and mental deterioration. AJNR Am J Neuroradiol 13:1225-1230, 1992

59. Perren F, Clarke S, Bogousslavsky J: The syndrome of combined polar and paramedian thalamic infarction. Arch Neurol 62:1212-1216, 2005

60. Petropoulou KA, Gordon SM, Prayson RA, Ruggierri PM: West Nile virus meningoencephalitis: MR imaging findings. AJNR Am J Neuroradiol 26:1986-1995, 2005

61. Poppe AY, Watson TW, Hudon ME, Puetz V, Wang W: A reversible cause of "vascular dementia". Neurology 71:226, 2008
62. Racine CA, Lawton MT, Hetts SW, Josephson SA: Neuropyschological profile of reversible cognitive impairment in a patient with a dural arteriovenous fistula. Neurocase 14:231238, 2008

63. Rodan LH, Mishra N, Tein I: MR spectroscopy in pediatric Wernicke encephalopathy. Neurology 80:969, 2013

64. Sachs E: Diagnosis and Treatment of Brain Tumors. St. Louis: C. V. Mosby, 1931

65. Santillan A, Safdieh JE, Gobin YP, Patsalides A: Neurological picture. Bilateral thalamic venous hypertension caused by a tentorial dural arteriovenous fistula: endovascular treatment. J Neurol Neurosurg Psychiatry 82:749-750, 2011

66. Satomi J, van Dijk JM, terBrugge KG, Willinsky RA, Wallace MC: Benign cranial dural arteriovenous fistulas: outcome of conservative management based on the natural history of the lesion. J Neurosurg 97:767-770, 2002

67. Schmahmann JD: Vascular syndromes of the thalamus. Stroke 34:2264-2278, 2003

68. Shah MN, Botros JA, Pilgram TK, Moran CJ, Cross DT III, Chicoine MR, et al: Borden-Shucart Type I dural arteriovenous fistulas: clinical course including risk of conversion to higher-grade fistulas. J Neurosurg 117:539-545, 2012

69. Simon S, Yao T, Ulm AJ, Rosenbaum BP, Mericle RA: Dural arteriovenous fistulas masquerading as dural sinus thrombosis. J Neurosurg 110:514-517, 2009

70. Smith AB, Smirniotopoulos JG, Rushing EJ, Goldstein SJ: Bilateral thalamic lesions. AJR Am J Roentgenol 192:W53W62, 2009

71. Söderman M, Pavic L, Edner G, Holmin S, Andersson T: Natural history of dural arteriovenous shunts. Stroke 39:1735-1739, 2008

72. Strom RG, Botros JA, Refai D, Moran CJ, Cross DT III, Chicoine MR, et al: Cranial dural arteriovenous fistulae: asymptomatic cortical venous drainage portends less aggressive clinical course. Neurosurgery 64:241-248, 2009

73. Sugrue PA, Hurley MC, Bendok BR, Surdell DL, GottardiLittell N, Futterer SF, et al: High-grade dural arteriovenous fistula simulating a bilateral thalamic neoplasm. Clin Neurol Neurosurg 111:629-632, 2009

74. Swartz RH, Black SE: Anterior-medial thalamic lesions in dementia: frequent, and volume dependently associated with sudden cognitive decline. J Neurol Neurosurg Psychiatry 77:1307-1312, 2006

75. Szirmai I, Vastagh I, Szombathelyi E, Kamondi A: Strategic infarcts of the thalamus in vascular dementia. J Neurol Sci 203-204:91-97, 2002

76. Tamamoto F, Nakanishi A, Takanashi T, Ishizaki H, Nagasawa H, Maehara T, et al: Unexpected accumulation of thallium-201 in bilateral thalamic venous infarction induced by arteriovenous fistula in the posterior fossa: report of a case. Ann Nucl Med 17:239-243, 2003

77. Tanaka K, Morooka Y, Nakagawa Y, Shimizu S: Dural arteriovenous malformation manifesting as dementia due to ischemia in bilateral thalami. A case report. Surg Neurol 51:489-494, 1999

78. Tominaga T, Shamoto H, Shimizu H, Watanabe M, Yoshimoto T: Selective loss of Purkinje cells in transverse and sigmoid dural arteriovenous fistulas. Report of two cases. J Neurosurg 98:617-620, 2003

79. van Dijk JM, Willinsky RA: Venous congestive encephalopathy related to cranial dural arteriovenous fistulas. Neuroimaging Clin N Am 13:55-72, 2003

80. van Dijk JMC, terBrugge KG, Willinsky RA, Wallace MC: Clinical course of cranial dural arteriovenous fistulas with long-term persistent cortical venous reflux. Stroke 33:12331236,2002

81. van Rooij WJ, Sluzewski M, Beute GN: Dural arteriovenous fistulas with cortical venous drainage: incidence, clinical 
presentation, and treatment. AJNR Am J Neuroradiol 28:651-655, 2007

82. Waragai M, Takeuchi H, Fukushima T, Haisa T, Yonemitsu T: MRI and SPECT studies of dural arteriovenous fistulas presenting as pure progressive dementia with leukoencephalopathy: a cause of treatable dementia. Eur J Neurol 13:754759, 2006

83. Wicklund MR, Knopman DS: Brain MRI findings in Wernicke encephalopathy. Neurol Clin Pract 3:363-364, 2013

84. Willinsky R, Goyal M, terBrugge K, Montanera W: Tortuous, engorged pial veins in intracranial dural arteriovenous fistulas: correlations with presentation, location, and MR findings in 122 patients. AJNR Am J Neuroradiol 20:1031-1036, 1999

85. Wilson M, Doran M, Enevoldson TP, Larner AJ: Cognitive profiles associated with intracranial dural arteriovenous fistula. Age Ageing 39:389-392, 2010

86. Wilson M, Enevoldson P, Menezes B: Intracranial dural arterio-venous fistula. Pract Neurol 8:362-369, 2008

87. Yamakami I, Kobayashi E, Yamaura A: Diffuse white matter changes caused by dural arteriovenous fistula. J Clin Neurosci 8:471-475, 2001

88. Yamamoto T, Watanabe M, Miura A, Hirahara T, Hirano T, Uchino M: [A case of dural arteriovenous fistula associated with bilateral thalamic lesions.] Rinsho Shinkeigaku 50:718-724, 2010 (Jpn)

89. Zeidman SM, Monsein LH, Arosarena O, Aletich V, Biafore JA, Dawson RC, et al: Reversibility of white matter changes and dementia after treatment of dural fistulas. AJNR Am J Neuroradiol 16:1080-1083, 1995

90. Zhang LJ, Zhong J, Lu GM: Multimodality MR imaging findings of low-grade brain edema in hepatic encephalopathy. AJNR Am J Neuroradiol 34:707-715, 2013

91. Zipfel GJ, Shah MN, Refai D, Dacey RG Jr, Derdeyn CP: Cranial dural arteriovenous fistulas: modification of angiographic classification scales based on new natural history data. Neurosurg Focus 26(5):E14, 2009
92. Zuccoli G, Gallucci M, Capellades J, Regnicolo L, Tumiati B, Giadás TC, et al: Wernicke encephalopathy: MR findings at clinical presentation in twenty-six alcoholic and nonalcoholic patients. AJNR Am J Neuroradiol 28:1328-1331, 2007

93. Zuccoli G, Pipitone N: MR Imaging: an increasingly important tool in the early diagnosis of Wernicke encephalopathy. AJNR Am J Neuroradiol 33:E92-E93, 2012 (Letter)

\section{Disclosures}

Dr. Derdyn reports that he is a consultant for Penumbra, MicroVention, and Silk Road, and has direct stock ownership in Pulse Therapeutics. Dr. Moran reports that he is a consultant for Medtronic Neurovascular. Dr. Lanzino reports that he is a consultant for Covidien and Medtronic.

\section{Author Contributions}

Conception and design: Zipfel, Holekamp, Derdeyn, Rich. Acquisition of data: Holekamp, Mollman, Kolar, Kramer, Derdeyn, Moran, Lanzino. Analysis and interpretation of data: Zipfel, Holekamp, Mollman, Murphy, Kolar, Perrin, Rich. Drafting the article: Holekamp, Mollman. Critically revising the article: Zipfel, Holekamp, Murphy, Derdeyn, Moran, Perrin, Rich, Lanzino. Reviewed submitted version of manuscript: Zipfel, Holekamp, Mollman, Murphy, Derdeyn, Moran, Perrin, Rich, Lanzino. Approved the final version of the manuscript on behalf of all authors: Zipfel. Statistical analysis: Holekamp, Mollman. Administrative/technical/material support: Zipfel. Study supervision: Zipfel.

\section{Correspondence}

Gregory J. Zipfel, Department of Neurological Surgery, Washington University, Campus Box 8057, 660 S. Euclid Ave., St. Louis, MO 63310.email: zipfelg@wustl.edu. 